\title{
ROMPIMENTO COM A TRADIÇÃO - REM KOOLHAAS
}

\author{
Gabrielly Gomes Munhoz, Mariane Miranda Sant'ana, Korina Aparecida Teixeira \\ Ferreira da Costa. \\ Universidade do Oeste Paulista - UNOESTE, Curso de Arquitetura e Urbanismo, Presidente \\ Prudente,SP. E-mail: gabriellyg_munhoz@hotmail.com
}

\section{RESUMO}

O presente artigo tem como objetivo fazer um estudo de uma das maiores obras do arquiteto holandês Rem Koolhaas, a Sede da CCTV, situada em Pequim, na China. Koolhass rompe com aquilo que vinha sendo projetado na contemporaneidade, distorcendo uma obra ícone do tradicional moderno, o Seagram, e dando origem à Sede da CCTV. A obra em estudo se difere da massa de edifícios lineares a sua volta por possuir um loop interligando suas duas torres e fazendo com que atue como um todo. Devido ao loop, foi necessária uma estrutura complexa e resistente a abalos sísmicos. Essa soma de fatores origina uma obra espetacular, que rompe com a tradição e se destaca na paisagem, podendo ser vista de formas diferentes de cada parte da cidade.

Palavras-chave: Rem Koolhaas, Rompimento com a tradição, Arquitetura Contemporânea, Sede CCTV, Desconstrutivismo.

\section{BREAK WITH TRADITION - REM KOOLHAAS}

\begin{abstract}
This article aims to study one of the greatest works by the Dutch architect Rem Koolhaas, the CCTV Headquarters, located in Beijing, China. Koolhass breaks with what was projected in contemporary times, distorting an icon work of the traditional modern, the Seagram, and giving rise to CCTV Headquarters. The work under study differs from the mass of linear buildings around it by having a loop connecting its two towers and causing it to act as a whole. Due to the loop, a complex, seismic-resistant structure was required. This sum of factors originates a spectacular work, that breaks with the tradition and stands out in the landscape, being able to be seen of different forms of each part of the city.

Keywords: Rem Koolhaas, Breaking with tradition, Contemporary Architecture, CCTV Headquarters, Deconstructivism.
\end{abstract}




\section{INTRODUÇÃO}

Com a quebra da Bolsa de Valores de Nova Iorque em 1929, os Estados Unidos da América alcança o ápice da grande Depressão, que teve como consequência a desativação da escola de design Bauhaus, a mais influente no mundo todo, consequentemente perdendo grandes nomes da arquitetura. (BENEVOLO, 1998; KARNAL, 2007).

Após vencer a crise e o término da Segunda Guerra Mundial, os Estados Unidos ressurgem como maior potência econômica, política e militar, motivando o orgulho da população à cidadania (KARNAL, 2007).

Em meio a este contexto, em 1968, Rem Koolhaas iniciou sua formação em arquitetura na Architectural Association em Londres, posteriormente fundando o OMA (Office of Metropolitan Architecture) juntamente com seus ex professores Elia Zenghelis, Zoe Zenghelis e Madelon Vriesendorp. Em 1989 houve um momento decisivo, onde o escritório começou então a passar de projetos de pequena escala, como a Villa dall'Ava, a projetos de grande escala, pelos quais são conhecidos hoje, como a Biblioteca de Seattle (considerada um dos mais importantes edifícios do século XXI), e a obra estudada neste artigo, a Sede dar CCTV, eleita o "Melhor Edifício em Altura do Mundo" (LYNCH, 2016).

Com base na bibliografia contextualizada, o presente trabalho tem por objetivo apresentar as características e aspectos da contemporaneidade do desconstrutivismo do arquiteto Rem Koolhaas, e a obra da Sede da CCTV, juntamente com o rompimento do tradicional.

\section{METODOLOGIA}

A presente pesquisa é de cunho qualitative e foi realizada através de uma síntese de informações teóricas, obtidas por meio de bases de dados digitais e livros sobre a arquitetura contemporânea e o rompimento com a tradição. Onde primeiramente, procurou-se compreender como se deu o rompimento com a arquitetura tradicional, tendo como objeto de estudo a Sede da CCTV, projeto do renomado arquiteto Rem Koolhaas. Em seguida, por meio da bibliografia de CHING (2013), foram exercidas relações entre sua forma imprevisível e sua estrutura complexa com a nova arquitetura, evidenciando o porque deste edifício desconstrutivista ter se tornado um ícone arquitetônico.

\section{RESULTADOS}

Na Europa, a partir do século XV, houve uma mudança de pensamento, onde Deus, a figura central da sociedade, foi substituído pela ciência, que era guiada pela razão. (TOURAINE, 1994). Surge então o Movimento Moderno, que tentou simplificar a arquitetura ao fazer o despojamento de toda a ornamentação da tradição clássica, revelando-se puro e funcionalista. A pós-modernidade nasce no final dos anos 1970, com o fim do Modernismo, abandonando uma série de ideias e de noções características do estilo.

Sequencialmente, a Arquitetura Contemporânea se inicia no final dos anos 80 e é marcada por diferentes influências. Como características dos projetos arquitetônicos, o estilo revela a mistura de várias tendências, como o Moderno e o Pós-Moderno em um comportamento definido como pluralismo, além do uso de materiais sustentáveis e aproveitamento da luz natural. (FAGUNDES, 2014).

$\mathrm{Na}$ década de 90, Peter Eisenman, juntamente com a influência de Jacques Derrida, se apropriou desse momento, criticando o raciocínio previsto e lógico, e 
incorporou estes conceitos em sua teoria arquitetônica, criando uma nova vertente que dava um novo significado aos elementos geométricos da arquitetura, instigando novas percepções e sentidos de espaço. (COLIN,2010).

Segundo Andrade (2011), Eisenman publica um artigo em 1984 - "O fim do clássico: o fim do começo, o fim do fim"- criticando a Arquitetura Moderna, que se dizia ser uma ruptura radical com os padrões, sendo que a mesma não havia questionado as três ficções: representação, razão e a história. Eisenman e Derrida discutem sobre a origem, e se completam ao dizer que "para reconstruir o intemporal (...) é preciso começar eliminando os conceitos clássicos (...) de origem e fim” (EISENMAN,1984, p.243).

Em 1932, Philip Jhonson, então curador do Museu da Arte Moderna (MoMA), realizou a "Exposição de Arquitetura Moderna" com o objetivo explícito de definir o estilo internacional. Em 1988, o mesmo, agora ao lado de Mark Wigley, decidiu executar uma outra exposição, mas esta com uma abordagem oposta à primeira, contrária a uma arquitetura fiel às regras, uniformizada e seguindo princípios projetuais (FIEDERER, 2017). Desta vez, selecionou trabalhos de arquitetos como Rem Koolhaas, Peter Eisnman, Zaha Hadid e Frank Gehry, por terem uma abordagem semelhante e com resultados similares (FIEDERER, 2017), realizando uma arquitetura que não seguia regras e nem propunha um novo estilo, apenas buscava mostrar a estética da obra e como ela se formalizava, gerando uma reflexão em torno dos outros movimentos arquitetônicos.

Sendo assim, a nova vertente arquitetônica, conhecida como "Desconstrutivismo", pretende romper com as tradições da Arquitetura Contemporânea, principalmente as formas puras. Procuram, através da tortura das formas clássicas, criar:

[...] uma arquitetura sinuosa, uma arquitetura escorregadia, que desliza descontroladamente do familiar para o desconhecido, até uma estranha tomada de consciência de sua propria natureza estranha, uma arquitetura, finalmente, que se distorce a si mesma para revelar-se de novo. (WILGLEY,1988, p.20).

O desconstruir é referente à desconstrução de significados, sem relembrar o passado e nem projetar o futuro, ativando facetas desconhecidas dentro das teorias já existentes, colocando em causa conceitos básicos, como o da parede, que perde a função de delimitar espaços, e da janela, que passa a ser uma forma regular que atravessa uma parede sólida (MARQUES, 2013, p.26). O desconstrutivismo está em despir a obra de toda ornamentação e transformar a sua pureza em algo instável e inesperado, para que dessa essêcia pura surjam impurezas, causando admiração do observador, que se surpreende com a complexidade da construção.

\section{DISCUSSÃO}

Remment Lucas Koolhaas começou a chamar a atenção do público e da crítica a partir de 1975, quando, juntamente com os arquitetos Madelon Vriesendorp - sua esposa -, Elia Zenghelis e Zoe Zenghelis, fundou em Londres, o OMA - Office for Metropolitan Architecture- e, posteriormente, a sua contraparte orientada para a pesquisa, a AMO, atualmente baseada em Rotterdam. Mais tarde, juntaram-se a eles Zaha Hadid, uma das alunas de Koolhaas, e outros parceiros.

Um dos primeiros trabalhos que iria marcar a diferença do grupo do classicismo pós-moderno no final dos anos 1970, foi a contribuição para a Bienal de Veneza de 1980, sob a curadoria de Paolo Portoghesi, denominada Presença do Passado. Cada arquiteto tinha que projetar uma rua interna típica para uma vila de Potemkin - uma espécie de vila cenográfica - e o esquema do OMA foi a única proposta modernista. 
A comissão para chefiar os projetos do Euralille, em 1989, foi um momento decisivo, quando o escritório passou a realizar obras de grande escala, como a Sede da CCTV. Contudo, a influência do OMA não se limita ao seu diverso portfólio. Talvez ainda mais importante seja o fato do escritório ser uma "incubadora" de talentos, orgulhando-se de ex-colaboradores como Zaha Hadid, Joshua Prince Ramus, Bjarke Ingels, e Jeanne Gang. (LYNCH, 2006.) Koolhaas delineia uma arquitetura engajada e multidisciplinar, foi laureado como Prêmio Pritzker e curador da Bienal de Veneza de 2014.

[...] penso que temos que olhar de outro modo para a disciplina da arquitetura em relação ao mundo. Se há várias possibilidades entre fazer mudanças no mundo e deixá-lo como está, o arquiteto está sempre do lado da mudança. Se essas possibilidades se estendem entre executar ideias e observá-las, o arquiteto está sempre do lado da execução. (KOOLHAAS, 2006 s/p).

\section{OBRA EM ESTUDO - SEDE DA TV DA CHINA(CCTV)}

Para Koolhaas (2017, p.06), "qualquer organização complexa é desmantelada, já que cada parte é colocada em um local visando o mínimo de dinheiro". Assim não há ligação entre os blocos e não existe a ideia de um todo. Desta forma, para realizar o projeto da nova Sede da TV Central da China, Rem Koolhaas sabia que havia um espaço conceitual que poderia acomodar a construção da CCTV como um todo - uma única entidade na qual todas as partes fossem abrigadas permanentemente - conscientes da presença de cada uma. O local em questão, escolhido para abrigar a nova sede da CCTV, que deveria estar pronta durante os jogos Olímpicos de 2008, se encontra no novo Distrito Central de Negócios de Pequim, perto da interseção da Avenida Chang'an e do Terceiro Anel Viário, no norte da China, em um sítio de $180.000 \mathrm{~m}^{2}$ (KOOLHAAS, 2017, p.06).

Em seu conceito, Koolhaas (2017, p.09) imaginou um edifício cuja forma tridimensional oferecesse ao pessoal de CCTV para executar as funções dentro de um "circuito contínuo", referindo-se à um circuito fechado de televisão, o que acabaria se tornando um desafio para a engenharia. Para ser possível, o edifício teria que consistir em duas torres, onde uma se inclina para a outra e se encontram em uma direção perpendicular, com balanço de 75m (DELAQUA, 2012, p.02), formando um loop como uma cruz em $Z$, o que reinventaria o arranha- céu, que até então era sempre uma torre linear, bidimensional, e que buscava ser cada vez mais alta.

Koolhass $(2017$, p.08) relata que em 2003, durante uma discussão sobre o projeto em uma universidade chinesa, ao ser questionado pela complexidade da obra, ele rebateu dizendo

[...] quem diz que essa estrutura não deve ser reinventada? [...] eu simplesmente peço que você esclareça os termos pelo qual você nomeia essa estrutura impraticável. É viável [...] É simplesmente uma maneira de apoiar e permitir que outras formas de arquitetura surjam. Não é apenas esta forma, uma vez que está provado que podemos construí-la, não é apenas este edifício que será realizado com um esforço incrível e escandaloso, mas também libertará centenas de outros arquitetos, bons e maus como de costume. mais experimental e se render menos a uma ditadura da gravidade.(KOOLHAAS, 2017 p.20)

O edifício é visível da maior parte de Pequim; às vezes aparece grande e às vezes pequeno, de alguns ângulos fortes e de outros suaves. Se destaca na paisagem por romper a massa de torres lineares que há a sua volta. Com sua forma diferenciada consegue emoldurar vistas da cidade e os pisos na fachada refletem os outros edifícios do entorno, além de desfazer a noção de escala humana, dando a sensação de ser mais monumental do 
que realmente é.

Percebe-se que a composição formal da torre acontece através de uma transformação subtrativa da forma, onde se tem a existência de um grande trapézio com uma parcela de seu volume central retirado. Já na planta baixa a organização acontece de forma linear. Por serem facilmente reconhecidas, as formas geométricas simples, como os sólidos primários, adaptam-se prontamente ao tratamento subtrativo. Essas formas conservaram suas identidades formais por ocasião da remoção de porções de seus volumes sem a deterioração de suas arestas, cantos e perfil global. (CHING, 2013, p.52)

Formado apenas de linhas retas, com ângulos retos que só existem na dimensão horizontal e na parte externa quando toca o chão, possui uma simetria radial bruta quando é visto do nordeste, sem nenhum círculo ou arcos verdadeiros e sem formas geométricas comuns, assemelhando-se a um fenômeno natural, desordenado, pelo movimento sinuoso que é gerado (KOOLHAAS, 2017, p.11).

"É uma reinvenção dos arranha-céus como um laço" (DELAQUA, VITOR, 2012). Não é previsível e por isso se torna impactante, pois impressiona o observador, onde o tal imagina a dificuldade de execução de um edifício assim. Deste modo, apesar de manter o despojamento de ornamentação, característica do Modernismo, o edifício de Rem Koolhaas tem aspectos da contemporaneidade, mas que rompe com a tradição das formas puras e previsíveis, tornando-o algo inovador e sublime (DELAQUA, VITOR,2012).

O projeto estrutural da China Central Television (CCTV) foi fornecido por Cecil Balmond e Arup, enquanto ECADI (East China Architectural Design \& Research Institute) funcionou com o Instituto de Projeto Local. (DELAQUA, 2012). A estrutura combina simetrias e assimetrias, parecendo de início simples, consistindo em 6 blocos, aproximadamente retangulares (dois na base, dois verticais e 2 formando uma saliência), organizados em forma de "L" e sugerindo uma sobreposição geométrica (KOOLHAAS, 2017, p.11).

É na verdade um único rombóide irregular escavado no centro, um loop encurralado, tendo o corpo denso e etéreo, com vidro de placa penetrante, exposição substancial de características internas à visão externa e visões panorâmicas de todo nível dentro. Sua macroestrutura é tubular e ourobórica. Além disso, sua característica saliente é uma instabilidade visualmente intuitiva (KOOLHAAS, 2017, p.11)

Seu centro de gravidade não é aparente e não possui relação com o centro de massa, ocasionando um problema que desafia a gravidade e que em seguinte é resolvido de forma elegante, interligando contrapeso, complementaridade e reciprocidade, onde a distribuição de peso aparece com base em uma interdependência dinâmica: dos 6 blocos, 4 podem manter a integridade estrutural apenas na presença de todos os 4 ; apenas os 2 contíguos com a Terra, formando a base em forma de L, são estáveis em isolamento. As torres pressionam suas cabeças juntas, como se cada uma estivesse cansada pelo esforço de permanecer em pé, já que nenhuma das duas suportaria se a outra cedesse (KOOLHAAS, 2017, p.11)

A estrutura visível e tangível do CCTV, em sua forma final, apresenta uma escala variável de densidade no arranjo de hastes angulares, de forma que mais contraventamentos aparecem em áreas sujeitas a maior tensão, o que torna a obra surpreendente por uma ilusão ótica (KOOLHAAS, 2017, p.11). Assemelha-se a uma ponte e desafia a gravidade a 80 metros de altura, rompendo com a linearidade do moderno e se tornando dinâmico, instável, com uma teia fragmentada, que se estende pela pele de vidro e, segundo Koolhaas (2017, p.12), devido a seus materiais inorgânicos, mas que 
apresentam caracteríticas de vida, colaboram para as alterações da forma.

Devido à sua forma incomum, certas áreas da superfície do CCTV parecem suportar cargas perigosamente desproporcionais, enquanto outras permanecem relativamente poupadas, sendo a solução descartar a densidade uniforme dos membros diagonais e abraçar a irregularidade (KOOLHAAS, 2017, p.11)

Nessa nova arquitetura de Eisenman, há vários tipos para a desconstrução de um edifício e entre eles está o utilizado por Rem Kolhaas na obra analisada, que é a desconstrução do solido geométrico. (COLIN, 2009). Eisenman apresentou esse tipo de processo a partir do Seagram Building em Nova York (1954-1958), de Ludwig Mies Van der Rohe- edifício que representou um extremo do ideal moderno arquitetônico de Estilo Internacional- onde o mesmo desconstruiu aquele paralelepípedo de aço e vidro, resultando-se no edifício Max Reinrardt Haus, em Berlim (1933), com uma forma totalmente imprevisível e surreal, aparentando ter sido amassado.

Rem Koolhas faz o mesmo com a CCTV, na China, se igualando esse processo de desconstrução e distorção desse edifício típico moderno tradicional, o Seagram, como fez Eisenman. Apesar dos três edifícios serem parecidos estruturalmente, suas formas são totalmente diferentes, com a Sedesendo o Seagram quebrado e dobrado em várias partes, onde Koolhaas desmonta a forma pura de Mies e o fragmenta. Enfim, o edifício é a desconstrução do plano material (paredes, vigas, pilares, esquadrias), que desobedecem uma logística clássica.

\section{CONCLUSÃO}

Em suma, através das informações adquiridas e analisadas acima, pode-se concluir que o arquiteto Rem Koolhaas tem a sua concepção baseada na desconstrução do solido geométrico, fazendo com que, dessa maneira, a obra em si tornesse sinuosa, imprevisível e impactante. Isso se deve ao fato de que o mesmo não vê limites no quesito estética, ou seja, é capaz de romper com as tradições, quebrando as formas puras existentes, pois acredita que mais importante é a estética final do que os meios que a interligam.

Adepto a desafios arquitetônicos, optou ousar no projeto estudado, reinventando o arranha-céu. A arquitetura praticada tem como principais características a tecnologia e o contraste, como é possível perceber claramente na aplicação do mesmo. Koolhaas desejou quebrar estes paradigmas justamente para libertar os arquitetos de uma ditadura de gravidade existente, inspirando-os a serem mais audaciosos e experimentais.

Portanto, é possível dizer que o edifício da China Central Television possui inúmeros aspectos da contemporaneidade, mantendo o despojamento com características do modernismo. Entretanto, foi capaz de romper com a previsibilidade e com a linearidade do moderno, caracterizando-o como inovador e hiper-realista.

\section{REFERÊNCIAS}

ARCHDAILY. CLÁSSICOS DA ARQUITETURA: EXPOSIÇÃO DESCONSTRUTIVISTA DE 1988 NO MOMA. Disponível em , <https://www.archdaily.com.br/br/870436/classicos-daarquitetura-exposicao-desconstrutivista-de-1988-no-moma $>$. Acesso em 08 de Agosto de 2018.

ARCHDAILY. EM FOCO: REM KOOLHAAS. Disponível em <https://www.archdaily.com.br/br/01-153678/feliz-aniversario-rem-koolhaas>. Acesso em: 18 de maio de 2018. 
ARCHDAILY. FUNDAMENTOS DA ARQUITETURA CONTEMPORÂNEA. Disponível em $<$ https://www.archdaily.com.br/br/01-106915/fundamentos-da-arquitetura-contemporaneaslash-siegbert-zanettini>. Acesso em: 18 de maio de 2018.

ARCHDAILY. CCTV HEADQUARTERS/OMA. Disponível em: $<$ https://www.archdaily.com/236175/cctv- headquarters-oma>. Acesso em 24 de maio de 2018.

CCTV HEADQUARTERS. Disponível em <https://en.wikiarquitectura.com/building/cctvheadquarters/>. Acesso em: 24 de maio de 2018.

CHING, Francis D. K. Arquitetura - Forma, Espaço e Ordem. São Paulo: Martins Fontes, 2013. COLIN, Silvio - O FAZER DESCONSTRUTIVISTA. Disponível em: $<$ https://coisasdaarquitetura.wordpress.com/2011/12/23/desconstrutivismo/amp/>. Acesso em: 24 de maio de 2018.

EISENMAN, Peter - O fim do clássico: o fim do começo, o fim do fim, 1984.

OMA OFFICE WORK SEARCH. Disponível em <http://oma.eu/projects/cctv-headquarters>. Acesso em: 20 de maio de 2018.

MARQUES,G. Arquitetura desconstrutivista: aplicação a um projeto prático. 2013. Dissertação (Mestrado em Arquitetura e Urbanismo) - Faculdade de Engenharia, Universidade da Beira Interior, Covilh 